\title{
HISTORICIDADES EM CONFLITO: UMA HIPÓTESE PARA O SÉCULO XX
}

\author{
Carlos Eduardo Ribeiro ${ }^{1}$ \\ Universidade Federal do ABC (UFABC) \\ (D) https://orcid.org/0000-0002-0902-5429 \\ E-mail: c.ribeiro@ufabc.edu.br
}

\section{RESUMO:}

Levanto a hipótese de que duas historicidades predominaram na relação estabelecida entre os discursos filosófico e histórico no século XX: a historicidade dos historiadores, suscitada pelo nascimento das ciências humanas, e uma historicidade filosófica em que o mito humanista persiste, especialmente dentro do debate que opôs estrutura e diferença. Esta segunda configura-se como uma eliminação da historicidade dos historiadores à medida que elabora muito mais demandas de historicidade próprias ao modelo estrutural.

PALAVTRAS - CHAVE: Contemporaneidade; Historicidade; Foucault; Ciências humanas.

\section{HISTORICITIES IN CONFLICT: A HYPOTHESIS FOR THE 20TH CENTURY}

\begin{abstract}
:
I argue that two historicities have predominated in the relation between philosophical and historical discourses in the 20th century. One is the historicity of historians, engendered by the birth of the humanities. The other is a philosophical historicity in which the humanist myth persists, especially within the debate opposing structure and difference. This second historicity represents an elimination of the first, as it elaborates many more demands of historicity inherent to the structural model.
\end{abstract}

KEYWORDS: Contemporaneity; Historicity; Foucault; Humanities.

\footnotetext{
${ }^{1}$ Doutor(a) em Filosofia pela Universidade de São Paulo (USP), São Paulo - SP, Brasil. Professor(a) da Universidade Federal do ABC (UFABC), São Bernardo do Campo - SP, Brasil.
}

RIBEIRO, Carlos Eduardo. Historicidades em conflito: uma hipótese para o século XX. Griot : Revista de Filosofia, AmargosaBA, v.21 n.3, p.35-49, outubro, 2021. 


\begin{abstract}
“A verdade não escapará de nós" - essa frase, de Gottfried Keller, descreve o lugar exato em que o materialismo histórico rompe com a imagem que o historicismo tem da história. Pois se trata de uma imagem irrecuperável do passado, que ameaça desaparecer com cada presente, a qual |que | não se reconheceu visado por ela. [A boa nova, que o historiador do passado porta com pulsações velozes, vem de uma boca que, talvez no instante mesmo em que se abre, fala no vazio. ] (BENJAMIN, 2020 p. 393).
\end{abstract}

\title{
Introdução
}

$\mathrm{O}$ conceito de história no século $\mathrm{XX}$ recebeu tantas formulações que poderíamos reivindicar para este período aquilo que Augustin Thierry evocava para seu tempo: a história como emblema de um século totalmente voltado aos historicismos. No entanto, sabemos que os historiadores no século XIX, diante do processo de formação da disciplina que se institucionalizava e se delimitava como ciência e campo autônomo, "tiveram a tarefa de escrever a biografia da nação. Ao fazê-lo contribuíram para construir, do ponto de vista imaginário, a própria nação" (SANTOS, 2001, p. 177). Diferentemente, o século XX terá a necessidade de produzir conceitos de História já um tanto distanciado do apelo historicista, que conhecemos desde Ranke, e movido, se não pela experiência da nação, certamente, em parte, pelo impacto dos conflitos mundiais dos quais nossas distopias mais reais nasceriam.

É verdade que seria impossível tentar uma generalização qualquer do conceito de história no século $X X$, seja dentro do campo da historiografia, seja de um ponto de vista da filosofia do século XX. Em 1940, um pouco antes de fugir das tropas germânicas e desaparecer na fronteira entre a França e a Espanha, Walter Benjamim escrevia as teses Sobre o conceito de história. Sua reflexão filosófica sobre a História não é uma Filosofia da racionalidade histórica, tendo sido animada muito mais pelo "insucesso" acadêmico do Filósofo e pelo avanço do nazismo na Europa (FUNARI, 1996). Qualquer pretensão de uma racionalidade peremptória para a história seria o mesmo que negar o presente histórico que Benjamim, em sentido estrito, atravessava. A urgência do tempo presente fazia Benjamim engajar suas teses no cerne de uma história combativa, de um renascimento do não-esquecimento ativo de coloração nietzschiana. Numa das versões manuscritas das Teses, Benjamim declara: "É necessária uma teoria da história, a partir da qual se possa encarar o fascismo" (BENJAMIM, 2020). A célebre tese XVII de Benjamim traduz em método o que, nessa declaração, é expresso quase como um rompante do desejo. Para Benjamim, encarar o tempo presente era, ao mesmo tempo, mover e suspender o pensamento:

\footnotetext{
O historicismo culmina com razão na História Universal. Talvez mais do que de qualquer outra, a historiografia materialista se afasta dela em seu método. A História Universal não tem uma armadura teórica. Seu procedimento é aditivo; ela usa a massa dos fatos para preencher o tempo homogêneo e vazio. Já o fundamento da historiografia materialista, por sua vez, é um princípio construtivo. $O$ pensar envolve não apenas o movimento dos pensamentos, mas também a sua suspensão (p. 1202).
}

Barrado nos Pirineus, Benjamim em 1940 pode ser visto como a metonímia da história do século XX: sua condição de preso na passagem manifesta a contemporaneidade excessiva ou um excesso de presente que irá saturar o século $\mathrm{XX}$.

Teremos muitas versões sobre essa suspensão do tempo no século XX. Muitas vezes lemos que foi o entreguerras e o pós-guerra que redefiniu a experiência de temporalidade da humanidade do século XX, a ponto de nos depararmos com o historiador Hobsbawm a cunhar a expressão era

RIBEIRO, Carlos Eduardo. Historicidades em conflito: uma hipótese para o século XX. Griot : Revista de Filosofia, Amargosa BA, v.21 n.3, p.35-49, outubro, 2021. 
dos extremos em face das megamortes produzidas até a década de 1990, cujo processo se remonta a 1914. O breve século $X X$ terminaria com o colapso da URSS (HOBSBAWM, 2008, p. 21), marca de um tempo outro para a história. Estamos certamente diante da imensa dificuldade de avaliar o alcance ou os reflexos dos conflitos mundiais sobre o pensamento do século XX e o que se sentiu como o presente de um tempo. Isso mesmo que um historiador do quilate de Hobsbawm nos tenha proposto a análise histórica, nada breve, sobre a qual não pesa dúvidas quanto à temporalidade outra, intensa e condensada, do século XX - que "viveu e pensou em termos de guerra mundial, mesmo quando os canhões e as bombas não explodiam" (HOBSBAWM, 2008, p. 30).

Outras "confirmações" poderiam nos conduzir a considerar os conflitos mundiais e seu tempo condensado como o grande traço determinante de como pensamos nosso presente: a Resistência francesa e a geração inteira de intelectuais e filósofos que foi desde aí produzida e a partir da qual podemos compreender o sentido de engajamento em face do inimigo comum. A mesma Resistência ratificava para Arendt, na menção que faz a René Char (ARENDT, 2016 p. 28), a quebra entre passado e futuro diante da evidente necessidade colocada pelo pós-guerra de dimensionar uma herança deixada sem testamento. Geração, sem dúvida, indiscutivelmente ligada ao contundente presente da II Guerra Mundial, como se observa na formação dos pensadores de Frankfurt. Para Adorno - para mencionar apenas um destacado entre eles -, elaborar o passado devia ser a tarefa política de uma autoconsciência: evitar Auschwitz. Tal proposta se traduziria em nada menos que na pesquisa empírica de intervenção de Personalidade autoritária: uma espécie de pesquisa de contraesclarecimento sobre como, no interior da experiência democrática dos EUA, produziam-se as raízes mais profundas, psíquicas e coletivas, da personalidade antidemocrática e/ou fascista (ADORNO, 2019).

Poderíamos simplesmente acatar o argumentum magister dixit e concluir que o século XX nos legou a temporalidade da guerra total, marcando definitivamente o modo como pensaríamos doravante. Mas considerar as coisas assim não seria mais um esquema totalizante? A história não parece ser um jogo de reflexos condicionados.

\section{Uma historicidade de historiadores}

A tentativa de explicar o século XX e o que nele se pensou mediante a experiência da guerra total nos conduz ao problema da ambiguidade do próprio surgimento da filosofia da história. Segundo Le Goff, é possível explicar essa ambiguidade por um reiterado jogo de espelhos que, na realidade, nos vem desde os antigos. Tal ambiguidade pode ser indiciada pela compreensão do vocábulo história. Ele teria a raiz comum grega, de origem indo-europeia, no vocábulo historie: ver ou testemunhar (o vettas no sânscrito, a "testemunha" histor, no grego): "historein" em grego antigo é "procurar saber", "informar-se". Historie significa, pois, "procurar". É este o sentido da palavra em Heródoto, no início das suas Histórias, que são "investigações", "procuras" (LE GOFF, p. 18). Mas ele complementa:

nas línguas românicas (e noutras), 'história' exprime dois, senão três, conceitos diferentes. Significa: 1) esta "procura das ações realizadas pelos homens" (Heródoto) que se esforça por se constituir em ciência, a ciência histórica; 2) o objeto de procura é o que os homens realizaram. Como diz Paul Veyne, "a história é quer uma série de acontecimentos, quer a narração desta série de acontecimentos" [1968, p. 423]. Mas a história pode ter ainda um terceiro sentido, o de narração. Uma história é uma narração, verdadeira ou falsa, com base na "realidade histórica" ou puramente imaginária — pode ser uma narração

RIBEIRO, Carlos Eduardo. Historicidades em conflito: uma hipótese para o século XX. Griot : Revista de Filosofia, Amargosa BA, v.21 n.3, p.35-49, outubro, 2021. 
histórica ou uma fábula. $O$ inglês escapa a esta última confusão porque distingue entre history e story (história e conto). As outras línguas européias esforçam-se por evitar esta ambigüidade. $O$ italiano tem tendência para designar se não a ciência histórica, pelo menos as produções desta ciência pela palavra 'storiografia'; o alemão estabelece a diferença entre a atividade "científica", Geschichtschreibung, e a ciência histórica propriamente dita, Geschichtswissenschaft. Este jogo de espelhos e de equívocos manteve-se ao longo das épocas (LE GOFF, 1990, p. 18-19, último grifo nosso).

Coube justamente ao século XIX trilhar um caminho diferente deste movimento oscilante que ora confere valor ao testemunho do acontecimento, ora reconhece a explicação científica. Esse caminho é trilhado, conforme Le Goff, pelo que se denominou de historicismo/historicidade. Se o historicismo vai desenhando um discurso unificador de uma história do homem ou da cultura é porque essas duas pontas (testemunho - narração, ou em termos mais novos, acontecimento narrar o acontecimento ou fazer a ciência dele) se traduzem em uma necessidade monolítica de enraizar os saberes numa história e de tomar esse enraizamento como "categoria do real", como expressa o historiador francês. Enquanto o historicismo é a norma de um discurso explicativo num tempo, a historicidade é o valor construído comum a todos os homens (p. 19). São injunções próprias de um século que, ainda não condensado no tempo e no espaço do privilégio antropológico, prepara-se, entretanto, para narrar as verdades históricas da condição humana.

Basta ver que uma história natural tentava apreender o desenvolvimento das sociedades humanas como história do gênero humano. A história natural passa a ser contraposta a uma história científica cujo esforço é o que o século XIX procurou descrever como a evolução das sociedades humanas enquanto tais. Reside aí a possibilidade de um passo central para a consolidação da história como modelo de racionalidade. Nos últimos 20 anos do século XX, a história como historiografia é este momento no qual se decide que tudo é histórico, inclusive a racionalidade histórica. A chamada "história da história" tem a necessidade de determinar a própria evolução, não só da sociedade humana, como da ciência histórica mesma dentro de uma percepção de "desenvolvimento histórico global" (LE GOFF, 1990 p. 8). No limite, aquele jogo de espelho se reflete no contemporâneo "afastamento existente entre a 'realidade histórica' e a ciência histórica". Precisamente isto, a inoperabilidade crescente entre o fato humano e os fatos de história, teria permitido "a filósofos e historiadores propor — da Antiguidade até hoje sistemas de explicação global da história (para o século XX, e em sentidos extremamente diferentes, podem ser lembrados Spengler, Weber, Croce, Gramsci, Toynbee, Aron etc.)" (LE GOFF, 1990, p. 10).

Consequência central, portanto: a filosofia da história é o mais importante subproduto desta nova razão histórica que passa a se interrogar sobre como podemos estabelecer uma função comum aos homens sob um mesmo ideal de humanidade. Em outros termos, Kant, em sua filosofia, que primeiro reconheceu no próprio movimento da História um movimento da razão, só tem a chance de afirmar a emancipação universal porque ela se inscreve na ambição — que se tornará mais evidente no século XIX —na qual uma temporalidade homogênea inventa o problema que não tínhamos: investigar a desconhecida "intenção da natureza" (KANT, 1990, p. 22). Mas a intenção última da natureza não é o mundo, seus ciclos ou a Providência divina. A intenção última da natureza é, sem dúvida, o homem. É claro que o projeto kantiano da filosofia da história não se esgotou em perseguir filosoficamente o percurso do gênero humano numa simples aplicação da razão à história. Era preciso que interviesse o acontecimento bruto, isto é, investigar como o gênero humano se reparte em movimentos antropológicos particulares. Mas isto 
não alterou os destinos da filosofia da história: ao se pensar a história filosoficamente, ela se fechará sobre si numa disciplina misteriosa e restrita a teorizar sobre a escolha humana pela liberdade.

Acontece que foi o historiador, e não o filósofo, do século XX que acordou mais cedo do sono antropológico (FOUCAULT, 1999, p 470-473). A partir disso, poderemos constatar que o século XX desenvolveu o historicismo em duas perspectivas — certamente, não as únicas, mas as mais decisivas para o discurso filosófico. Uma é o historicismo que podemos chamar de profícuo epistemologicamente, ligado às ciências humanas como campo de problematização do homem tornado objeto. Outra é um historicismo que estabelecerá a divisão, pelo menos até meados dos anos 1960, entre a história dos historiadores e um discurso filosófico metodologicamente autorreferido.

Primeira perspectiva: a historicidade, condição humana tornada comum de humanidade, opera com um desempenho ambíguo para si mesma e desde o seu interior. Para facilitar a exposição do argumento, podemos apoiar este sentido no próprio surgimento da etnologia e da psicanálise. Ele se mostra uma resposta do humanismo: por um lado, é a reiterada pergunta antropológica pelo que é e pelo que pode o homem. Mas é, por outro lado, um surgimento que retira o privilégio do homem como norma: quem é este homem que se determina por aquilo que não é, a saber, uma cultura e um inconsciente? A resposta radicalizaria o ideal de humanidade historicista, afirmando um espaço em branco: se há sociedades, há diferentes histórias; se há funcionamento psíquico inconsciente, há singularidades. Entre outras coisas, isso implica necessariamente na vontade de saber que se põe a perguntar: "quem são estes humanos das diferentes sociedades?" ou "quem são estes sujeitos singulares?" Etnologia e clínica transferencial pertencem, no século XX, ao mesmo ímpeto da morte do homem desde um questionamento pelo seu ser.

Evidentemente, refiro-me ao conhecido diagnóstico foucaultiano que, depois de propor sua arqueologia das ciências humanas, coloca no lugar da disposição epistêmica moderna (o Homem) as contraciências. Temos a flagrante contradição com um ideal de humanidade que se dá porque a historicidade se aninha na finitude indefinida do homem, que é tanto o surgimento das ciências humanas quanto o das contraciências humanas; que é tanto o rosto que aparece com figura finita e repartida em positividades, numa dada concretude, quanto o rosto que desaparece na orla do mar, isto é, sob o indefinido. Historicidade ambígua, em suma, porque, se "o homem só se dá ao saber positivo na medida em que fala, trabalha e vive", como poderia ser sua história, perguntase Foucault, "outra coisa senão o nó inextrincável de tempos diferentes, que lhe são estranhos e que são heterogêneos uns em relação aos outros?" (Idem, p. 511). Esse diagnóstico atinge fortemente a prática histórica do século XX como uma verdadeira mutação epistemológica para ela. Por exemplo, a mutação no uso do documento que, de matéria inerte e totalizadora do passado, modifica-se como valor inerente ao tecido do presente:

O documento não é o feliz instrumento de uma história que seria em si mesma, e de pleno direito, memória; a história é, para uma sociedade, uma certa maneira de dar status e elaboração à massa documental de que ela não se separa.

Digamos, para resumir, que a história, em sua forma tradicional, se dispunha a "memorizar" os monumentos do passado, transformá-los em documentos e fazer falarem estes rastros que, por si mesmos, raramente são verbais, ou que dizem em silêncio coisa diversa do que dizem; em nossos dias, a história é o que transforma os documentos em monumentos e que desdobra, onde se decifravam rastros deixados pelos homens, onde se tentava reconhecer em profundidade o que tinham sido, uma massa de elementos que

RIBEIRO, Carlos Eduardo. Historicidades em conflito: uma hipótese para o século XX. Griot : Revista de Filosofia, Amargosa BA, v.21 n.3, p.35-49, outubro, 2021. 
devem ser isolados, agrupados, tornados pertinentes, inter-relacionados, organizados em conjuntos. (FOUCAULT, 2002 p. 8)

Como Foucault, Le Goff enxerga uma importante renovação epistemológica nas ciências humanas já que se tratou de desvincular a historicidade de suas raízes ligadas ao historicismo do século XIX. Se quisermos um breve balanço, podemos resumir dizendo que as ciências humanas, ao retirar o amparo do mito humanista pelo seu duplo necessário (as contraciências), lograram a enorme vantagem de serem racionalidades com concretudes sempre reponentes. Estava decretada a possibilidade, doravante sempre em aberto, de um "objeto" possível para uma ciência dita humana, fato que os séculos XX e XXI confirmaria sobremaneira ao multiplicar as racionalidades do campo. Podemos falar de uma historicidade dos historiadores que vai se configurando como campo bastante discernível no século $\mathrm{XX}$, já que não haveria mais ciências humanas sem esta pergunta pela historicidade como discurso sobre uma práxis social, seja esta fornecida pela própria ciência histórica ou pela psicologia, pela psicanálise, pela literatura etc. Das diferentes versões do marxi-freudismo aos encontros de certas "filosofias" com a teoria política ou a história da ciência, isto é, de um Adorno ou um Deleuze a uma Arendt ou Foucault, invariavelmente a práxis social teria de ser convocada no discurso das ciências humanas ou por ela visada. E, com ela, uma historicidade radical sobre o presente se encetaria.

Quando no início mencionei que a história não parecia ser um jogo de reflexos condicionados é porque não bastava dizer que o século das grandes guerras impactou o pensamento desse período senão que esses pensamentos seriam constrangidos, no inelutável dos acontecimentos, ao seu presente. Se se quiser apreender de modo cabal essa historicidade a que as ciências humanas deram lugar, basta que tenhamos em conta uma comparação com o nosso presente: que a pandemia do novo coronavírus é este inelutável a nos impelir, devido ao alto grau de quebra entre passado e futuro, à resultante da reflexão. Mas isso não significa que toda capacidade de elaborarmos pensamentos nesse tempo se deva exclusivamente ao fato imposto, mas sim ao que se poderá pensar, e só aí, nesse intervalo tão severo quanto producente. Os corpos sentados nas janelas virtuais não dispõem de tempo a mais; dispõem de sede de existências outras. Esta é a historicidade dos historiadores, uma pedra dura contra a qual se topa, mas que não se vê. Sua dureza tece o presente como reflexão. E esta torna-se condição primeira de vida.

Enquanto isso, quero dizer, enquanto se constituíam as ciências humanas século $\mathrm{XX}$ adentro, a antiga rainha das ciências, a filosofia, desenvolve certa descendência de negação dessa historicidade. Era como se ela quisesse manter sua soberania, mas já destituída das insígnias reais pelas quais se podia reconhecer sua nobreza.

Daí que uma segunda perspectiva de historicidade se desenha para o século XX. Trata-se da rendição de algumas filosofias do século XX a uma historicidade historicista conforme se pode localizar nelas uma recusa da historicidade dos historiadores. Estrutura e acontecimento, aporia tão revistada nas filosofias denominadas de estruturalistas e pós-estruturalistas, podem fornecer uma ideia do que aconteceu. Como porta de entrada para a referida negação, a conjunção entre os dois conceitos é um legado dos trabalhos de Saussure e problematizava originalmente as dimensões da sincronia e diacronia do desenvolvimento da língua. Mas o que poderia ter passado para a história das ciências humanas no século XX como um fundo epistemológico comum à filosofia e às ciências humanas tornar-se-ia, a contrapelo, o cavalo de batalha para certains philosophes des soixante: 
Já há bastante tempo que os historiadores identificam, descrevem e analisam estruturas, sem jamais se terem perguntado se não deixavam escapar a viva, frágil e fremente "história". A oposição estrutura-devir não é pertinente nem para a definição do campo histórico nem, sem dúvida, para a definição de um método estrutural (FOUCAULT, 2002, p. 13, grifo nosso).

\section{Uma historicidade a contrapelo: estrutura e diferença nos soixante}

Priorizei expor até aqui a produção discursiva da historicidade dos historiadores cuja consequência central é, no fundo, ela estar intimamente ligada à constituição dos objetos e positividades das ciências humanas. Para não deixar margem a dúvidas sobre esta historicidade dos historiadores, digamos as coisas claramente: o historiador, no século XX, é um dos sujeitos praticantes das ciências humanas, mas um praticante especial porque é aquele que efetivamente realiza, em sua prática de cientista social, a historicidade dessa ciência. Se a historiografia é a história da história (a ciência da história), o historiador é a condição de existência de qualquer historicidade. Vale para o historiador de modo direto o mecanismo de dobradiça que opera o campo epistêmico moderno:

História que concerne agora ao ser mesmo do homem, pois que se evidencia que não somente ele "tem", em torno de si, "História", mas que ele mesmo é, em sua historicidade própria, aquilo pelo que se delineia uma história da vida humana, uma história da economia, uma história das linguagens (FOUCAULT, 1999, p. 512).

Essa não é uma simples coincidência, porque, afinal, ela altera completamente o quadro de inserção da disciplina histórica no conjunto das ciências humanas: esse homem, que está implicado na ciência histórica, deverá lançar sua historicidade na qualidade de um intérprete. Para dizer de outro modo, o ofício do historiador tem contato direto com este "(...) nível muito profundo, uma historicidade do homem que seria, por si mesma, sua própria história, mas também a dispersão radical que funda todas as outras". (Idem, p. 512).

$O$ efeito vem em benefício da organização discursiva da historiografia que deve ser vista assim: na expressão de Foucault, a História é, na verdade, mãe das ciências do homem, é a mãe de todas as histórias, de todas as historicidades vindouras (FOUCAULT, p. 508):

A partir do século XIX, o que vem à luz é uma forma nua da historicidade humana - o fato de que o homem enquanto tal está exposto ao acontecimento. Daí a preocupação, seja de encontrar leis para esta pura forma (e têm-se filosofias como as de Spengler), seja de defini-la a partir do fato de que o homem vive, de que o homem trabalha, de que o homem fala e pensa: e têm-se as interpretações da História a partir do homem considerado como espécie viva, ou a partir das leis da economia, ou a partir dos conjuntos culturais (Idem, p. 512-513).

Em descompasso com a historicidade do historiador, as filosofias do século $\mathrm{XX}$ se verão diante de dois impedimentos interligados. Em primeiro lugar, elas terão resistência em admitir a si mesmas como discurso perimetral ${ }^{2}$ em relação à ambiguidade epistemológica que caracteriza as ciências humanas, com seus métodos, objetos e procedimentos que transitam entre diferentes

\footnotetext{
${ }^{2}$ Com a expressão discurso perimetral expresso genericamente a ideia foucaultiana, conceituada de muitos modos, de que uma figura do saber é sempre a emersão de uma formação discursiva, efeito de superposições de positividades de uma dada ciência.
}

RIBEIRO, Carlos Eduardo. Historicidades em conflito: uma hipótese para o século XX. Griot : Revista de Filosofia, Amargosa BA, v.21 n.3, p.35-49, outubro, 2021. 
saberes. Basta nos perguntarmos, por exemplo, se seríamos capazes de ao menos imaginar a filosofia acatando para si, como organização discursiva legítima, o que ocorreu no percurso da sociologia. Nesta, os campos de atuação intensificaram-se e diversificaram-se a tal ponto que todas as sociologias sentem entre si efeitos de colateralidades, dependências de teorias coirmãs e vínculos de metodologias intercambiáveis. Em todo caso, se não pode ser a rainhas das ciências humanas, a filosofia também parece não querer sair do trono. É assim que, em segundo lugar, ela já possui outro impedimento. Não podendo mais praticar-se simplesmente como discurso monodiscursivo sobre o homem, ela terá diante de si a fatura impagável de vislumbrar a terra antropológica e seus duplos nas ciências humanas, mas de falar deles desde a incômoda posição de um reingresso numa historicidade humanista. Tudo se passa como se a filosofia quisesse repor os vínculos da antiga historicidade do século XIX (historicidade explicativa, com suas leis gerais e sistemas) na tentativa de fugir da central "disposição da História no espaço epistemológico" (FOUCAULT, 1999, p. 513).

Para compreendermos esse reingresso, apoio-me na análise de Frédéric Worms em seu livro La philosophie en France au XXe. Siècle. Worms fornece uma interessante caracterização da geração dos anos 1960 que ele denomina de Estrutura e diferença: o momento filosófico dos anos 60 na França. Em síntese, essa caracterização propõe que o problema originário desse momento é a relação conceitual entre estrutura e diferença. Trata-se de um problema inaugurado na linguística estrutural de Saussure, especificamente nos cursos de linguística geral que Saussure proferiu na primeira década do século XX na Universidade de Genebra.

A estrutura é um problema filosófico, segundo Worms, porque nela está implicada a tensão entre o homem e suas formas individuais oferecidas pela linguagem. O modelo da linguística de Saussure carregaria esta questão muito básica de ter valor local e dimensão da existência humana, ao mesmo tempo que se apresenta como conhecimento geral sobre o próprio homem. Neste modelo, continua Worms, aparece a afirmação tensionada de que todas as ciências humanas, as ciências humanas em geral, são tanto nossa existência individual e geral, quanto que ela se mostra acessível a nós apenas "por meio das estruturas entendidas como sistema de signos" (WORMS, 2009, p.469).

Dando por certa a morte do antigo projeto de ciências do espírito, o século XX assistirá às consequências efetivas da duplicação do homem nas diversas ciências humanas. Saussure passou, assim, a ter de se haver com essa dificuldade quando expôs, com esforço, a necessidade de delimitar o objeto próprio da linguística. Esse objeto aparece como um singular-universal que se positiva na singularidade da língua, mas que igualmente aspira à universalidade enquanto discurso de ciência. Este vai-e-vem entre uma estrutura especificada e a diferença efetiva que a língua produz sobre o homem nela compreendido nos confinaria nos muros da querela "estrutura ou acontecimento?". Em síntese, a partir de Saussure teríamos produzido uma ideia de homem como objeto de um modelo racional singular-universal que se verá em xeque a cada vez que justamente uma nova concretude da língua for objeto de pesquisa. Vamos reter essa problematização, nomeando-a de a demanda de historicidade da estrutura.

Mas além dessa tensão constitutiva entre estrutura e diferença, haveria, ainda segundo Worms, dentro própria ideia de estrutura uma segunda tensão, a saber, entre sistema e diferença. Dois aspectos inseparáveis estão embutidos na ideia de estrutura que, como sabemos, é fundamental para o modelo da linguística: a estrutura é uma "totalidade sistemática" porque nada numa língua faz sentido isoladamente, mas exige sempre num "sistema de relações". A estrutura se avalia "por seu lugar num todo, que tem, doravante, sua necessidade e que dá

RIBEIRO, Carlos Eduardo. Historicidades em conflito: uma hipótese para o século XX. Griot : Revista de Filosofia, Amargosa BA, v.21 n.3, p.35-49, outubro, 2021. 
também seu rigor próprio a ciência que estuda" (WORMS, 2009, p.470). Em outros termos, a estrutura implica um sistema de relações que, no limite, coloca a necessidade de um discurso como o das ciências humanas. Todavia, lembra o pensador francês, um sistema de relações é um sistema de oposições, isto é, de diferenças no qual "cada signo é tomado no movimento de passagem perpétuo de um signo a outro" (Idem, p. 470).

Daí, então, que a diferença entra em tensão com a totalidade do sistema. É nesta segunda tensão constitutiva do problema da estrutura que Worms propõe especificamente situar os pensamentos de Foucault, Derrida, Deleuze e Lyotard. No caso de Foucault, Worms apresenta As palavras e as coisas como um livro que representaria "a extensão do modelo da estrutura e da língua ao conjunto das ciências humanas" (Idem, p. 482) cujo motivo filosófico mais importante teria sido tematizado na morte do homem (como não constituir o homem, mas dissolvê-lo, como dizia Lévi-Strauss). Uma arqueologia das ciências humanas, que elabora um jogo discursivo de diferença constante entre as epistèmés, é a extensão do modelo da linguística ao conjunto das ciências humanas. Ao buscar os transcendentais correspondentes às diferentes concretudes do homem, Foucault faria operar a própria tensão entre estrutura e sistema, entre o homem que produz um discurso cuja concretude é ele mesmo. Vamos reter essa problematização, nomeandoa como a demanda de historicidade do sistema.

O que podemos visualizar nessas duas demandas de historicidade que seria comum a uma geração inteira e elaborada com insistência recorrente? Que a problemática estrutura e diferença é um rescaldo da historicidade historicista porque a dupla demanda mostra a tentativa de definir a historicidade, não pela prática do historiador, mas sim segundo uma apreensão do movimento histórico pelo conceito. É mais uma conceituação de história que uma crítica histórica. No lugar da historicidade do historiador se processa, para o campo filosófico, uma saturação do conceito de história a tal ponto que mesmo Foucault (que, em seu fazer intelectual, era mais arquivista que filósofo - talvez mais historiador-arqueólogo que epistemólogo) tem de assumir esse ônus no movimento de seu pensar. Ele é explícito no entendimento de que a oposição estrutura e história/devir é um modo de reativar, astuciosamente, a função fundadora do sujeito e de seus correlatos antropológicos dentro do que poderia ser visto como um duradouro movimento de conservação do humanismo (Cf. FOUCAULT, 2002, p. 14-17). No entanto, A arqueologia do saber não deixa de ser uma intrincada reflexão metodológica cuja problemática de fundo poderia se resumir ao correlato problema desta geração. Ou Foucault não esteve respondendo a certos interlocutores sobre sua lanterna mágica e sobre como se relacionam as práticas discursivas e nãodiscursivas?

Paradoxalmente, ao se ver obrigada a administrar o paradigma da racionalidade das ciências humanas, essa filosofia contemporânea deixa entrar uma historicidade humanista, por assim dizer, pelas portas dos fundos. Esta é uma clareira também aberta por Le Goff. Retomando Ricoeur, atira contra a história da filosofia:

Um filósofo como Paul Ricoeur vê na supressão da historicidade através da história da filosofia o paradoxo do fundamento epistemológico da história. De fato, segundo Ricoeur, o discurso filosófico faz desdobrar a história em dois modelos de inteligibilidade, um modelo de acontecimentos (événementiel) e um modelo estrutural, o que leva ao desaparecimento da historicidade: "O sistema é o fim da história porque ela se anula na lógica; a singularidade é também o fim da história porque toda a história se nega nela. Chegamos a este resultado paradoxal: é sempre na fronteira da história, no fim da história que se compreendem os traços mais gerais da historicidade" [1961, pp. 224-25]. (LE GOFF, 1990, p. 20).

RIBEIRO, Carlos Eduardo. Historicidades em conflito: uma hipótese para o século XX. Griot : Revista de Filosofia, Amargosa BA, v.21 n.3, p.35-49, outubro, 2021. 
Na referência a Ricoeur, Le Goff localiza muito bem o fato de "o discurso filosófico" que ele menciona - sem nome próprio? - poder falar apenas em termos de acontecimento, ou em termos de estrutura como se se sua condição de aparecimento fosse dada unicamente na fronteira da historicidade das ciências humanas. No limite da historicidade dos historiadores, assim, o que nessa geração parece se exibir, com exceções certamente, é a divisão crescente entre a história dos historiadores e a historicidade dos filósofos. Esta é responsável por uma linhagem de reflexões sobre a história no século XX cujo traço distintivo foi a expulsão do campo filosófico do trabalho histórico. ${ }^{3}$

A título de uma conclusão parcial e procurando indicar um solo anterior sobre as duas perspectivas de historicidade levantadas, é interessante notar que essa divisão poderia remontar aos usos que a própria filosofia do século XIX fez da palavra historicidade, ou, mais exatamente, ao modo pelo qual a filosofia dela se apropria. Em $A$ memória, a história e o esquecimento, Ricoeur, estudando a novidade do termo historicidade em Heidegger, acaba remetendo-se a Hegel para elaborar uma trajetória do conceito. Hegel teria sido o responsável por aclimatar a Geschichtlichkeit na filosofia (RICOEUR, 2007). Ricoeur mostra que como opera a significação grega e cristã do termo em Lições sobre a história da filosofia em dois momentos fundamentais do espírito segundo Hegel.

Assim, Ricoeur observa que, em Hegel, existe a historicidade ligada à herança grega, a historicidade transmitida como um sentir-se em casa do homem europeu, portanto, como familiaridade) (Heimatlichkeit). Recorda também que o pensador alemão marca o surgimento de outra historicidade, de herança cristã, a partir da qual a o valor histórico se ligaria à questão da verdade (Cristo, o homem verdadeiro na história, que é o momento da verdade na história). Apesar da importância, digamos assim, dessas duas historicidades ao marcarem dois momentos do espírito, Ricoeur pondera que será o termo Geschichte que, "desde Herder, Goethe e os românticos alemães, carrega a marca de profundidade e de gravidade que assumirá o termo historicidade" (RICOEUR, 2007, p. 382). Com isso, Ricoeur procura concluir que o relevo está na história do espírito, o que acarreta pensar que uma história é sempre, e antes de tudo, uma história da razão e, talvez secundariamente, história de racionalidades.

Se quisermos, a historicidade é secundária em relação à trajetória do espírito de modo que “o problema que ele (Hegel) transmite a seus intérpretes e a seus sucessores é o da tensão entre verdade e história" (p. 382). Eis aqui a mesma divisão que procurei caracterizar, entre uma historicidade de historiador e uma historicidade a contrapelo: "Como pode, pergunta o filósofo (Hegel), o espírito ter uma história? Pelo caráter epocal da questão, a história filosófica já fez secessão em relação à história dos historiadores. A factualidade perdeu todo interesse filosófico; foi reduzida à mera narrativa (Idem, p.382. grifo nosso).

\footnotetext{
${ }^{3}$ A introdução de $A$ arqueologia do saber pode ser vista como um documento que, em seu conhecido vaivém argumentativo, porta a questão das duas perspectivas de historicidade aqui tematizada de modo manifestar a posição explicitamente. Sintomático disso é quando Foucault, num quase desabado, afirma: “(...) finalmente, somos levados a deixar de lado, como se jamais tivesse aflorado, todo este campo de problemas metodológicos que a história nova propõe hoje” (FOUCAULT, 2002, p. 15)
}

RIBEIRO, Carlos Eduardo. Historicidades em conflito: uma hipótese para o século XX. Griot : Revista de Filosofia, Amargosa BA, v.21 n.3, p.35-49, outubro, 2021. 


\section{Conclusão}

\section{Por uma historicidade na filosofia contemporânea: um efeito de dispersão nas ciências humanas}

Um exemplo final pode contribuir com esta reflexão que, no fundo, tratou de pensar a imensa a-historicidade da qual por vezes padece o campo filosófico quando pensa sua própria historicidade. O paradoxo que busquei expor é o fato de que uma reflexão filosófica sobre a história tem lugar quando a factualidade é desautorizada como conceito. Entretanto, é só aí que, ao que parece desde Hegel, a filosofia teve a chance de falar a linguagem de uma razão que se realiza na história. A história é da ordem de um retorno do reprimido para os filósofos que, segundo tentei caracterizar, se aproximaria de um mecanismo de clivagem entre duas historicidades. ${ }^{4}$

Mas vou inverter esse paradoxo e apresentar um contraparadoxo. Pensemos, pois, na expressão filosofia contemporânea e em como o sentido de atualidade define não um período histórico, mas um presente da filosofia. Lembremos também um grande fato de atualidade, de um grande e forte presente que por vezes caracteriza a dita filosofia contemporânea. Essa ideia de filosofia, quando a relacionamos aos pensadores do século XX, está associada, por vezes, aos reflexos e impactos oriundos da Primeira e Segunda Guerras Mundiais. Podemos mencionar $O$ homem revoltado (1951) de Camus ou A destruição da razão de Lukács (1954) para nos referirmos a dois exemplos bastantes diferentes em seus propósitos, mas que igualmente reagem, com fervores intelectuais próprios, ao novo tempo do mundo que se impôs com o século das grandes guerras.

Contudo, é pouco evidente de que modo uma rubrica como esta, filosofia contemporânea, veio a se definir pelo evento histórico que é, ele mesmo, configurado por narrativas históricas ou interpretações múltiplas - narrativas ou interpretações que não só atravessam os debates intrínsecos às historiografias dos dois conflitos mundiais, como também suscitam, nos diversos campos das ciências humanas e sociais, tantos outros debates e questões inerentes a esses campos quando consideram os eventos em seus fazeres científicos.

Para nos limitar apenas ao campo da história e avaliar a complexidade dessa questão, voltemo-nos às vertentes historiográficas da chamada Grande Guerra. Elas encontraram diferentes expressões ao longo de 100 anos. Remeto-me ao trabalho da historiadora Silvia Correia. Valendo-se das pesquisas do historiador norte americano Jay Winter e do francês Antoine Prost, Correia descreve como os autores distinguiram quatro diferentes tendências historiográficas da Primeira Guerra, chegando a uma quarta geração mais ligada à ideia de uma história transnacional:

\footnotetext{
Não obstante a resistente persistência de uma dimensão nacional nas políticas oficiais rememorativas que assinalam o centenário, não mais a historiografia se desligará de uma perspectiva transnacional. Decorre esta nevrálgica viragem de uma coexistente maturação da história política, social e econômica, mas essencialmente cultural, que traria para o palco da guerra sujeitos que não mais poderiam ser pensados apenas no âmbito de um tempo e espaço vedados pelas fronteiras do nacional (CORREIA, 2014, p. 651).
}

É de fundamental importância assinalar que essas tendências, assim descritas pelos historiadores, têm seus pontos de ancoragem eles próprios interpretativos. Poderíamos levantar alguns questionamentos da seguinte ordem: quando se fala de uma Guerra Mundial e a ela se associa as narrativas históricas vindas das nações em que o Conflito ocorreu, digamos, conflitos

${ }^{4}$ Os temas psicanalíticos subjacentes à minha leitura terão lugar em outro trabalho.

RIBEIRO, Carlos Eduardo. Historicidades em conflito: uma hipótese para o século XX. Griot : Revista de Filosofia, Amargosa BA, v.21 n.3, p.35-49, outubro, 2021. 
em solo, não estamos dizendo também que é desde essa centralidade política que se interpretou ou se constituiu o evento? Em contrapartida, o que foi, nestes anos da Primeira Guerra, sua interpretação na periferia do Conflito, nas nações que "de longe" nelas se envolveram ou que por ela, desde aí, foram também marcadas? Estou sugerindo, portanto, algo relativamente simples: que sob as historiografias reinantes, neste caso dos anos 1920 aos anos 1980 sobre a Primeira Guerra, haveria sempre a possibilidade de fazermos a história da história. Para falar de outro modo, permanece a interpretação no fundo vazio de todo fato.

Se, de certo modo, as historiografias discerníveis a respeito de um evento já fazem essa espécie de história das histórias praticadas, há ainda em aberto outra possibilidade de história, a história de como um evento se torna um evento, a história de como se produz a história enquanto ela vai se apresentando como a tessitura do real ou das emergências que realizam o presente, qualificando-o como um acontecimento. Darei um exemplo breve já na direção do que quero concluir com esta consideração sobre a Primeira Guerra.

A simples ideia de nação que está subsumida nas interpretações autoriza os historiadores caracterizarem a Primeira Guerra Mundial como uma guerra própria dos valores e da experiência política do Estado-nação que, como nova interpretação, se converteria, posteriormente, em "uma incursão comparativa e transnacional" e que "dominaria os primeiros anos do século XXI, não só trazendo novos temas para o centro do debate, mas também promovendo novas incursões em alguns dos temas mais tradicionais" (CORREIA, 2014, p. 657). Digo que ela subsumiu as interpretações porque, sem a ideia de nação, não se poderia caracterizar nem uma guerra voltada para a defesa dos valores nacionais (e assim, pensar um conflito como conflito de relações internacionais), nem se poderia dimensionar o processo no qual se almejou compreendê-la por meio da perspectiva comparativa, interdisciplinar, transacional (Correia, 2014).

Mas o que representa essa ideia de nação como Estado-nação? Quantas outras perspectivas conceituais e históricas se insinuariam nesta experiência que datamos desde o século XVII, ao menos em sua formação de longa duração? É bem verdade que poderíamos admitir o mesmo questionamento para todas as noções envolvidas na prática do historiador, o que nos conduziria a um retroceder infinito. Estaríamos presos à espiral infindável da interpretação. De interpretação em interpretação, sempre buscaríamos os alicerces de um solo narrativo em outro?

Por mais desconforto que esse aspecto nos cause, ele não é, contudo, um defeito de performance das ciências humanas como um todo. Tocamos, na realidade, em um dos aspectos centrais daquilo com o que tem de se haver a prática do historiador no século XX. Conceitos, ideias, noções que circulam na prática das diferentes ciências humanas são também as referências de apoio para a prática histórica, para não dizer que inevitavelmente aparecem como categorias do discurso histórico desde o qual o historiador profissional simplesmente tem de partir. Deveríamos, quanto a esta questão, portanto, encarar a tarefa imensamente complexa sobre o que foi praticar história no século XX para os próprios historiadores, em especial quanto à diversidade de campos que atravessaram e às descontinuidades que propuseram. Seria preciso, por exemplo, retomar tarefas como a que enfrentou François Dosse (1992), que, para o caso francês, traçou as grandes linhas desta história que vai desde a fundação do movimento dos Annales até a denominada Nova História.

Em A História em Migalhas temos um importante exemplo daquela possibilidade aventada mais atrás de uma história interna das historiografias e que me parece ser precisamente este infindável da interpretação histórica no século XX. Além da história da historiografia, teríamos esta série de recursos de que uma prática histórica passa a valer-se efetivamente. Embora

RIBEIRO, Carlos Eduardo. Historicidades em conflito: uma hipótese para o século XX. Griot : Revista de Filosofia, Amargosa BA, v.21 n.3, p.35-49, outubro, 2021. 
Dosse seja muito severo em caracterizar o surgimento dos Annales como um movimento quase fortuito, podemos sentir o temperamento altamente realista em compreender sobre o que ou contra quem uma prática em história se estabeleceu:

\begin{abstract}
Apresenta-se imediatamente como uma escola militante, à margem, que clama por socorro às ciências sociais para desestabilizar a história historicizante hegemônica; e apresenta-se como escola-mártir, vítima do ostracismo para não espantar seus parceiros eventuais. Essa escola recusa todo dogma, toda filosofia ou teoria da história, daí a grande plasticidade e mobilidade e a capacidade de integração no maior campo de pesquisas possível. A conjunção da estratégia sólida de alianças com o ecumenismo epistemológico permite à escola dos Annales eliminar seus rivais" (DOSSE, 1992 p. 21-22).
\end{abstract}

O que pretendi delinear com tais considerações finais sobre a prática do historiador no século XX e sobre certas tentativas de racionalizar filosoficamente a própria história da filosofia? Que o historiador do século XX é um devedor insciente das enganosas fronteiras das ciências humanas e pratica, no fundo, uma abertura interpretativa desde um ponto, de certo modo aleatório, fornecido pelo presente que pertence à historiografia que utiliza. Que o filósofo da história da filosofia pretende autorreferendar a racionalidade deste campo, recorrendo igualmente a um presente determinado por interpretações, mas que o falseia ao tentar elevar sua interpretação à condição de uma racionalidade própria, que estaria, em função do mito humanista persistente, impressa no movimento mesmo da história. Ranço desejoso de um curso regular para colocar a todos sob a Constituição perfeita da humanidade. Tanto na filosofia como na história, portanto, o que se denomina de história apresenta-se, não raras vezes, como um conceito-limite — não abertura de todos os segredos da razão e da humanidade, nem factualidade narrável, mas um fio de Ariadne sem fim pelo qual "um acontecimento só tem sentido numa série, o número de série é indefinido, elas não se ordenam hierarquicamente" e tampouco "convergem para um geometral de todas as perspectivas" (VEYNE, 1998, p. 34).

Diante dessas possibilidades assim esboçadas, o efeito generalizante da filosofia da história deve contentar-se com um efeito de dispersão. Teremos sempre a possibilidade de definirmos alguma filosofia contemporânea no século XX trançando uma genealogia das concepções introduzidas e produzidas nas tendências historiográficas. A filosofia contemporânea poderia ser, pois, o conteúdo conceitual que é praticado e definido, por exemplo, na ideia de nação ou de transnacional pelos historiadores do século XX? Vimos que as quatro gerações historiográficas parecem ter deslocado, na interpretação da Primeira Guerra, a nação para o transnacional. Ora, não existiria aí, nesse percurso, uma filosofia contemporânea em toda radicalidade que esse qualificativo temporal comporta? $O$ tempo do conceito identificado ao seu uso não situaria a filosofia contemporânea neste limiar de simultaneidade entre o que se interpreta e o modo como se interpreta? Há certamente nisso um filão interpretativo e uma imensa aleatoriedade, já que todo pensamento produzido numa historiografia poderia, no limite, ser também admitido como prática filosófica, mesmo se isso constituísse um enorme escândalo no terreno próprio da filosofia.

Parece-me, de todo modo, que um exercício experimental poderia ser feito: a filosofia contemporânea tanto é mais contemporânea não por aquilo que afirmaram os filósofos em suas obras enquanto tematização do presente, muito menos pelo nonsense da "ilusão dogmática" da filosofia da história (VEYNE, 1998, p. 35), mas por aquilo que as historiografias, e as demais práticas discursivas das ciências humanas, estabeleceram como o conjunto de conceitos que se articulam na intepretação do acontecimento. Filosofia contemporânea, pois, como as múltiplas

RIBEIRO, Carlos Eduardo. Historicidades em conflito: uma hipótese para o século XX. Griot : Revista de Filosofia, Amargosa BA, v.21 n.3, p.35-49, outubro, 2021. 
genealogias das práticas conceituais das ciências humanas. Organizada como que uma ofensa ao filósofo profissional, ${ }^{5}$ a historicidade da filosofia assim definida exigiria ir até o extremo radical daquilo que se pratica como conceito na História, inclusive da prática do próprio conceito de História.

Nessa tarefa estaria implicada uma singularização reflexiva do acontecimento, na qual, necessariamente, conceber o conceito de história só pode ocorrer ao praticá-lo sob a forma de alguma história. Quanto a isso, Foucault parece-me particularmente exemplar. Embora crescentemente se procure definir um Foucault filósofo (como se ele próprio não tivesse respondido a isso com o riso nietzschiano), foram muitas as vezes, e de muitos modos, que ele levou em frente esta simultaneidade entre prática e definição de história, deixando-nos o trabalho de perseguir os mil e um rastros de sua filosofia praticada como história e de suas histórias, criadoras de conceitos.

Mas que vantagem teria uma historicidade que é dispersão constante? É que não foi mero interesse intelectual de Foucault a opção por uma prática de atualidade do pensamento, sobretudo nos anos 1980, momento no qual se inseriu um necessário apelo ético em direção à autoformação da subjetividade. Parece que o filósofo e o historiador têm a tarefa comum de elaborar o passado como função política de produção da crítica do presente, função de (contra)esclarecimento subjetivo como autoconsciência. Sem isso, sempre há o risco de uma falsa imaginação histórica postular um homem ideal e, por exemplo, deixar de recordar que as condições favoráveis para o fascismo um dia foram gestadas na democracia (ADORNO, 2019; 2003).

\footnotetext{
${ }^{5}$ A experiência de contemporaneidade não pode se identificar ao fugidio ou ao inapreensível de uma atualidade abstrata como dispara a interpretação de Agamben (2009) que faz o sujeito retroceder (ou avançar, de todo modo, totalizar-se) como espírito sobre um enigmático presente de sombras no qual ele se resolve: um homo sacer, quase invariável em sua indefinição trans-histórica. Nenhuma metáfora ilustrativa sobre a neurofisiologia da visão permitiu a Foucault concretizar uma genealogia do poder psiquiátrico como uma prática médica constituída de batalha entre dois corpos, cujo enfrentamento determinaria a patologia mental como déficit epistemológico da medicina da doença mental. Esta, à diferença da medicina clínica, não possuía corpo algum para atuar e forçou, assim, o doente mental a produzir sintomas no grande teatro da Salpetrière. Em outros termos, só há contemporaneidade desde a formação de uma norma admitida por um discurso como norma racional e que, desde este ponto de valoração, trabalha para variar-se como poder. Por vezes, a interpretação do filósofo italiano parece resvalar numa atemporalidade subjetiva, certamente hegeliana e anti-nietzschiana, que nos parece inconsistente com a prática sempre regionalizada e anti-historicista de Foucault.
}

RIBEIRO, Carlos Eduardo. Historicidades em conflito: uma hipótese para o século XX. Griot : Revista de Filosofia, Amargosa BA, v.21 n.3, p.35-49, outubro, 2021. 


\section{Referências}

ADORNO, Theodor. W. Estudos sobre a personalidade autoritária. São Paulo: Editora Unesp, 2019.

ADORNO, Theodor W. Educação e Emancipação. $3^{\text {a }}$ Ed. São Paulo: Paz e Terra. Tradução de Wolfgang Leo Maar, 2003.

AGAMBEN, Giorgio. O que é o contemporâneo? e outros ensaios. Tradução de Vinícius Nicastro Honesko. Chapecó: Argos Editora, 2009.

ARENDT, Hannah. Entre o Passado e o Futuro. Trad. Mauro W. B. Almeida. São Paulo: Perspectiva, 2016.

BENJAMiM, Walter. Sobre o conceito de História. Alameda Casa Editorial. Edição do Kindle, 2020.

CORREIA, Silvana Adriana Barbosa. Cem anos de historiografia da Primeira Guerra Mundial: entre história transnacional e política nacional. Topoi (Rio J.), Rio de Janeiro,v. 15, n.29, p.650673, Dec. 2014. Disponível em: http://www.scielo.br/scielo.php?script=sci_arttext\&pid=S2237101X2014000200650\&lng=en\&nrm=iso. Acessado em 28 Abril 2018.

FOUCAULT, Michel. As palavras e as coisas. Trad. Salma Tannus Muchail. 8. ed. São Paulo: Martins Fontes, 1999.

FOUCAULT, Michel. A arqueologia do saber. Trad. Luiz Felipe Baeta Neves. 6. ed. Rio de Janeiro: Forense Universitária, 2002.

FUNARI Pedro Paulo A. "Considerações em torno das "Teses sobre filosofia da História" de Walter Benjamin". Crítica marxista, Campinas, no. 3. p. 45-53, 1996.

HOBSBAWM, Eric. A era dos extremos: o breve século XX (1914-1991). 10.ed. São Paulo: Companhia das Letras, 2008.

KANT, I. Ideia de uma história universal com um propósito cosmopolita. In: A paz perpétua e outros opúsculos. Trad. Artur Morão. Lisboa: Edições 70, 1990.

LE GOFF, Jacques. História e Memória. Trad. Bernardo Leitão [et al.] -- Campinas, SP Editora da UNICAMP: 1990.

RICOEUR, Paul. A memória, a história e o esquecimento. Tradução de Alain François. Campinas, SP: Editora da Unicamp, 2007.

SANTOS, Afonso Carlos Marques dos. "Nação e história: Jules Michelet e o paradigma nacional na historiografia do século XIX". Revista de História, São Paulo, n. 144, p. 151-180, june 2001. ISSN 2316-9141. Disponível em: <http://www.revistas.usp.br/revhistoria/article/view/18913>. Acesso em: doi:http://dx.doi.org/10.11606/issn.2316-9141.v0i144p151-180.

VEYNE, Paul. Como se escreve a história e Foucault revoluciona a história. Brasília: Editora UNB, 1998.

WORMS, Frédéric. La philosophie en France au XXe.siècle. Moments. Paris: Édition Gallimard, 2009.

Autor(a) para correspondência / Corresponding author: Carlos Eduardo Ribeiro. c.ribeiro@ufabc.edu.br

RIBEIRO, Carlos Eduardo. Historicidades em conflito: uma hipótese para o século XX. Griot : Revista de Filosofia, Amargosa BA, v.21 n.3, p.35-49, outubro, 2021. 